\title{
Reported outcomes in phase II studies of newly-diagnosed pulmonary tuberculosis
}

\author{
Laura J Bonnett ${ }^{1,2^{*}}$, Geraint Davies ${ }^{2}$ \\ From The 4th Meeting of the Core Outcome Measures in Effectiveness Trials (COMET) Initiative \\ Rome, Italy. 19-20 November 2014
}

\section{Background}

Tuberculosis (TB) remains a major killer amongst infectious diseases. Current treatment involves a four-drug regimen for at least six months. New drugs and regimens are required to shorten treatment duration, reduce toxicity and combat drug resistance however the optimal methodology to define the critical path for these regimens is not well-defined.

We undertook a literature review to summarise outcomes reported in phase II trials of patients with newlydiagnosed pulmonary $\mathrm{TB}$ to determine the necessity for a core outcome set in TB.

\section{Methods}

Relevant studies were identified by searching MEDLINE, EMBASE, LILACs and reference lists of included studies. All reported outcomes were considered.

\section{Results}

49 included phase II studies presented data on 24 historic drug combinations. The most commonly reported outcome (35 studies) was early bactericidal activity (EBA) although there was disagreement regarding a definition. The majority of studies defined EBA as the fall (sometimes mean rate of change) in $\log _{10}$ colony forming units (CFU) per ml sputum over various time points. Related outcomes such as CFU count were sometimes reported in preference (12 studies). Other popular outcomes included number of positive (20 studies) or negative cultures (4 studies) at selected time points while in others time to culture negativity was favoured (3 studies). In all cases there was disagreement as to which time points should be chosen with options ranging from two days to eight weeks. Results for

\footnotetext{
* Correspondence: L.J.Bonnett@liv.ac.uk

'Department of Biostatistics, Institute of Translational Medicine, University of Liverpool, Liverpool, Merseyside, L69 3GA, UK

Full list of author information is available at the end of the article
}

novel drug combinations are currently being analysed and will be presented.

\section{Conclusions}

There is large variation in the outcomes reported across phase II studies in TB. To utilise results of multiple studies, and thus identify the best treatment regimens for TB, a core outcome set needs to be developed. This would enable trial results to be more easily compared and combined, potentially leading to improved treatment strategies for patients with TB.

\section{Authors' details}

'Department of Biostatistics, Institute of Translational Medicine, University of Liverpool, Liverpool, Merseyside, L69 3GA, UK. ²Department of Clinical Infection, Microbiology \& Immunology, Institute of Infection and Global Health, University of Liverpool, Liverpool, Merseyside, L69 7BE, UK.

Published: 29 May 2015

doi:10.1186/1745-6215-16-S1-P7

Cite this article as: Bonnett and Davies: Reported outcomes in phase II studies of newly-diagnosed pulmonary tuberculosis. Trials 2015

16(Suppl 1):P7.

Submit your next manuscript to BioMed Central and take full advantage of:

- Convenient online submission

- Thorough peer review

- No space constraints or color figure charges

- Immediate publication on acceptance

- Inclusion in PubMed, CAS, Scopus and Google Scholar

- Research which is freely available for redistribution 